\title{
Aborto: uma visão humanística
}

\section{Em defesa da vida: aborto e direitos humanos.}

CAVALCANTE, Alcilene; XAVIER, Dulce (Orgs.).

São Paulo: Católicas pelo Direito de Decidir, 2006. 230 p.

Dos mais de 50 milhões de abortos induzidos a cada ano, por todo o mundo, cerca de metade é realizada sem condições de segurança. As interdições ao aborto não evitam sua prática e somente o tornam clandestino e inseguro. Com efeito, esse problema social desperta polêmica e coloca em campos opostos grupos que se autodenominam defensores do direito à escolha por parte da mulher e outros que criminalizam diretamente essa ação. Tais divergências têm sido objeto de opiniões que se circunscrevem não somente aos campos jurídicos ou da saúde, como também ao campo religioso e moral, tangendo o poder legislativo, a mídia e a opinião pública (p. 111). Compreendendo o aborto como um fato social total, ' uma vez que o tema perpassa tanto várias esferas da vida social como diferentes campos interdisciplinares, abordar esse tema é sempre um ato de coragem, uma vez que se refere a um problema que atinge todos os sujeitos - e, em particular, as mulheres de uma sociedade. Nessa perspectiva, o livro Em defesa da vida: aborto e direitos humanos, editado pelas 
Católicas pelo Direito de Decidir, ${ }^{2}$ uma coletânea de artigos e de entrevistas, é um exemplo concreto de defesa da vida das mulheres. Por paradoxal que possa parecer o título do livro, conforme destaca Maria José Rosado Nunes, os diferentes artigos defendem a dignidade das mulheres e a proteção da maternidade:

Nós escolhemos esse título "Em defesa da vida: aborto e direitos humanos" exatamente porque defendemos a legalização do aborto e estamos defendendo a vida das mulheres. Defendemos, por mais paradoxal que isso possa parecer, a dignidade da maternidade. Nós queremos que se pense a maternidade como um processo que é resultante de um ato humano de desejo, de vontade e de um assumir realmente aquela gravidez e não como um resultado de um processo biológico que começou, e que não me sinto no direito de interromper. ${ }^{3}$

O livro, organizado por Alcilene Cavalcante e Dulce Xavier, é dividido por temas que exploram questóes como a Vida, a Saúde, os Direitos e a Lei, e foi escrito por profissionais e militantes que lidam diretamente com a questão do aborto em suas práticas cotidianas, assim como por pesquisadores/as acadêmices/as que têm o aborto como objeto de investigação.

A primeira parte do livro aborda as complicadas e complexas questões que envolvem o início da vida e são discutidas por Leonardo Boff, teólogo e ex-padre católico, Maria José Rosado Nunes, coordenadora das Católicas pelo Direito de Decidir (CDD), Marco Segre, presidente de honra da Sociedade Brasileira de Bioética (SBB), e Ennio Candotti, presidente da Sociedade Brasileira para 0 Progresso da Ciência (SBPC).

Leonardo Boff, numa entrevista às integrantes da CDD, argumenta que o surgimento da vida deve ser entendido processualmente, uma vez que ela nunca está pronta e pode ser interrompida em qualquer momento, mesmo quando ela ainda não atingiu sua relativa autonomia. Para Boff, esse processo deve ser protegido ao máximo, entretanto se deve compreender que tal processo pode ser interrompido por múltiplas razões, estando, entre elas, a determinação humana.

Maria José Rosado Nunes destaca, em seu artigo "Aborto, maternidade e a dignidade da vida das mulheres", que a defesa incondicional da vida é pregada pela Igreja Católica, uma vez que, para essa instituição, "o aborto não tem história" (p. 23). Chama atenção ao fato de que os fundamentalistas têm uma concepção fortemente arraigada em relação à materni- dade e que para eles essa seria a expressão máxima do respeito pela vida humana, sendo o aborto sua negação mais absoluta. Rosado Nunes aponta para os deveres do Estado no que diz respeito às políticas de planejamento familiar. Nesse campo, a legalização do aborto, assim como a universalização do acesso aos serviços públicos e da garantia do exercício da plena cidadania, deveria realizar-se de acordo com a decisão das pessoas relativas à procrição. Lembra que Estados democráticos devem assumir responsabilidade de legislar para uma sociedade diversa e plural em que o político não deve ser influenciado por quaisquer crenças religiosas. Para a autora, normas que restrinjam a liberdade das mulheres, independentemente de seu credo religioso, as impedem de exercer seus direitos de cidadania, negando-lhes sua humanidade.

No artigo de Marco Segre, "Considerações éticas sobre o início da vida: aborto e reprodução assistida", o autor questiona, conforme já destaca no título, qual seria o parâmetro para determinar o início e o fim da vida humana. Observa que isso seria uma tarefa aparentemente simples para biólogos, mas impossível na esfera de uma reflexão filosófica que leve em conta a vida percebida pelo "sujeito". Segre argumenta que determinados critérios são necessários para tal definição, embora sejam aleatórios e devam ser reconhecidos para que se possa discutir bioética livremente. Critica a discussão sobre o início da vida através de dogmas ou de tabus e observa que, quando se apela para a ciência para demarcar o início da vida, o que se faz é uma utilização "religiosa" - nas palavras do autor - da observação científica, que apenas pode indicar o momento da fecundação.

Na continuidade, Ennio Candotti reforça a crítica já destacada pelos demais autores de que o início da vida se dá na fertilização do óvulo pelo espermatozóide, argumento adotado pela Igreja Católica em nome da defesa da vida. Em seu artigo "Na terra como no céu", Candotti alerta para o número de abortos realizados anualmente no Brasil e para as políticas de aborto adotadas em outros países e demonstra, através de alguns parágrafos da Constituição e do Código Civil Brasileiros, como os direitos das mulheres não estão sendo respeitados. Observa que as políicas públicas referentes à segurança, à alimentação, ao planejamento familiar, aos direitos reprodutivos devem estar ao alcance de todos para se garantir e promover a solidariedade humana. 
Na segunda parte do livro, Humberto Costa abre a discussão tratando os aspectos da saúde relativos ao aborto. Nessa entrevista, o médico psiquiatra e ex-ministro da saúde do governo Lula (2003-2005) responde a questões relativas às falhas do planejamento familiar no Brasil, as quais podem ser associadas à incidência de abortos clandestinos. Fala da responsabilidade dos sistemas de saúde público e privado, os quais devem viabilizar $o$ acesso por parte das pessoas, dando informações que auxiliem numa política de planejamento familiar mais organizada. Critica a visão preconceituosa e conservadora de alguns profissionais da saúde no atendimento às mulheres que realizaram clandestinamente um aborto e que buscam atendimento nos serviços de saúde, mas ao mesmo tempo chama atenção para o fato de que boa parte desses profissionais tem consciência de que o abortamento no Brasil é realmente um "problema de saúde pública". Dessa forma, finaliza sua entrevista apontando para o fato de que esses profissionais revejam suas concepções no que diz respeito ao tema.

Thomaz Rafael Gollop, no artigo "Abortamento por anomalia fetal", fala de sua experiência na participação da instalação, em abril de 2005, da Comissão Tripartite para a Revisão da Legislação Punitiva do Aborto. Reflete sobre como essa experiência demonstrou a necessidade de aprofundar as discussões relativas à Interrupção Seletiva da Gravidez (ISG), ou seja, interrupções por anomalias fetais. Com o advento das ultrassonografias, ele, como médico ginecologista, lembra que já questionava, há muitos anos, a Sociedade Brasileira para o Progresso da Ciência (SBPC) sobre qual seria a atitude dos médicos em face de um diagnóstico de patologia fetal, caso a mulher ou o casal não quisesse levar adiante uma gravidez com essas características. Nota que, passados trinta anos, o mesmo problema ainda está por ser compreendido pelos médicos e pela sociedade brasileira.

A ginecologista e obstetra Zenilda Vieira Bruno aborda em seu artigo as questões de saúde relativas ao "Abortamento na adolescência". A autora chama atenção para o atendimento precário das adolescentes nas unidades de saúde, nas quais não é oferecido apoio ou aconselhamento adequado para as jovens, que, por diversas vezes, entram no ciclo repetido da gravidez-abortamento. Ressalta que a incidência de óbitos na adolescência constitui uma grande preocupação social e que sua redução, assim como a redução da gravidez não desejada ou não planejada, depende de medidas eficazes que assegurem orientação, prevenção e suporte psicológico e social. A autora traz dados de uma pesquisa realizada em 2002 com adolescentes que engravidaram, num estudo comparativo entre as adolescentes que levaram a gravidez até o final e aquelas que tiveram aborto espontâneo ou aborto provocado.

A enfermeira Carmen Lúcia Luiz revela um panorama sobre o aborto a partir de sua larga experiência em enfermagem e, em particular, a partir de seu trabalho nos serviços de atenção às vítimas de violência sexual. Nesse artigo, sob o título "Mulheres em situação de abortamento: um olhar sobre o acolhimento", a autora observa que diferentes considerações sobre o aborto são construídas com bases em valores morais, religiosos e culturais. Critica a banalização da discussão em torno da questão "proteger o direito do feto x proteger o direito da mulher" ou na polêmica entre "ser contra" ou "ser a favor". Destaca que muitas mulheres em situação de abortamento sofrem punições por parte da equipe médica e de enfermagem e que tal realidade carece de mudanças urgentes por parte dos profissionais da saúde, que, segundo ela, "devem ter atitudes menos investigativas e punitivas". Do mesmo modo, fala da urgência em implantar estratégias de planejamento familiar mais eficazes, como também esclarece os procedimentos das Normas Técnicas do Ministério da Saúde (1999 e 2005), as quais propõem um protocolo de atendimento às vítimas de violência sexual.

Maria Berenice Dias, Daniel Sarmento, Roberto Arriada Lorea e Miriam Ventura nos deixam a par das questões relativas à terceira parte desse livro, dedicada ao tema do Direito, destacando a legalização e descriminalização do aborto, direitos (e deveres) constitucionais no Brasil e também em outros países.

A desembargadora do Rio Grande do Sul Maria Berenice Dias dá destaque, em sua entrevista, à lei que vigora no Código Penal Brasileiro de 1940 sobre o aborto. Para ela, essa lei tem como projeto preservar a moral familiar em detrimento da questão da dignidade da mulher. Observa que, mesmo o aborto sendo criminalizado, isso não impede sua prática na clandestinidade e argumenta que sua penalização se dá por influência da religião e por outros interesses lucrativos que enfatizam a perversidade da ação. Não cabe ao Estado, segundo Dias, definir o início da vida, uma vez que nem a ciência conseguiu fazê-lo. Além disso, de acordo 
com a desembargadora, as anomalias fetais graves, a exemplo da anencefalia, não devem ser consideradas abortos. Para ela, a solução jurídica seria a inclusão de um permissivo legal sobre essa questão no Código Penal Brasileiro.

Nessa mesma direção, o Procurador Regional da República do Rio de Janeiro e professor de Direito Daniel Sarmento ilustra, em seu artigo "Legalização do aborto e Constituição", um panorama das leis sobre o aborto em várias nações, argumentando que o Brasil deveria partilhar da solução adotada por grande parte dos países europeus que legalizaram a realização do aborto voluntário no primeiro trimestre da gestação. Observa que esses mesmos países também criaram mecanismos extrapenais para evitar a "banalização do aborto", a exemplo do planejamento familiar, da educação sexual e de uma rede de proteção social para as mulheres. Argumenta que não somente a Constituição, mas também a racionalidade e a moral, indicam a urgência de uma reformulação das leis brasileiras no que diz respeito ao aborto.

Na continuação da terceira parte do livro, o juiz gaúcho Roberto Arriada Lorea reflete sobre o direito ao aborto a partir dos argumentos de ordem pública válidos no mundo jurídico. Para tanto, Lorea recorre ao conteúdo de conferências internacionais, como a Conferência Mundial sobre Populações e Desenvolvimento (Cairo, 1994) e a IV Conferência Mundial da Mulher (Beijing, 1995), e também a decisões de organismos internacionais de solução de conflitos, demonstrando a necessidade de uma mudança urgente na legislação para garantir a proteção integral dos direitos humanos das mulheres, pois, segundo o autor, uma parcela significativa dos juristas brasileiros tem ignorado a relevância dessas conferências. Lorea oferece nesse texto uma abordagem estritamente jurídica do tema aborto, tendo como foco a orientação jurisprudencial sobre ele. Argumenta que a questão do aborto não recebeu a devida atenção por parte dos operadores do Direito, o que compromete a capacidade desses profissionais de enfrentar com profundidade tal assunto.

Miriam Ventura, advogada integrante da Rede Feminista em Saúde e Direitos Reprodutivos, pontua alguns avanços significativos no que diz respeito ao reconhecimento dos direitos das mulheres relativos aos seus direitos sexuais e reprodutivos, tanto no plano internacional como no nacional. Em seu texto intitulado "Descriminalização do aborto: um imperativo constitucional", ressalta que as recomendações das Conferências de Cairo e de Beijing refletem alguns desses avanços quando atribuem aos Estados a obrigação de reformular o tratamento dado ao aborto como um problema de saúde pública. Do mesmo modo, a Constituição Federal de 1988 estabeleceu algumas condições essenciais para a reformulação do Código Penal Brasileiro, estando entre elas a não-incorporação da proteção da vida desde a concepção. Considera que a desigualdade de direitos impõe às mulheres ônus sociais e pessoais infinitamente maiores do que aqueles impostos aos homens e questiona "como o Estado controla a vida reprodutiva dos homens" (p. 186) perante o controle explícito da vida reprodutiva das mulheres.

Fecham essa coletânea os textos de Gilda Cabral, Ivan Paixão e Jandira Feghali, que traçam aspectos da legislação brasileira sobre a elaboração de projetos de leis e as decisões tomadas a respeito deles.

Gilda Cabral, sócia-fundadora da ONG CFEMEA - Centro de Estudos Feministas e de Assessoria -, destaca como a Constituição Brasileira de 1988 pode ser considerada uma "Constituição cidadã", pois ela abriu e ampliou espaços democráticos e a participação direta dos cidadãos e cidadãs brasileiros/as. Cabral observa nessa entrevista que o CFEMEA trabalha suprapartidariamente junto aos parlamentares no Congresso Nacional, argumentando, negociando e buscando convencer esses representantes políticos sobre a questão do aborto. O principal argumento usado é laicidade do Estado, uma vez que boa parte dos políticos não separa suas manifestações religiosas de sua atuação política. Destaca que - maior desafio para alterar a legislação sobre o aborto no Brasil ainda é a sociedade. Para ela, a sociedade brasileira necessita de maiores informações sobre o tema e, sobretudo, conhecer que o aborto é real e praticado por milhares de mulheres. Lembra que o aborto clandestino realizado na precariedade afeta a saúde das mulheres e que os hospitais e profissionais da saúde devem tratá-las com dignidade, respeitando seus direitos humanos. Somente seguindo essas premissas, segundo a autora, as mulheres podem parar de morrer por complicações relativas aos abortos inseguros.

Ivan Paixão faz uma incursão na história do aborto, discutindo posteriormente o avanço da Constituição Federal de 1988 e a relação do Estado com a Igreja Católica. "Aborto: aspectos da legislação brasileira" é um artigo que chama 
atenção às restrições da legislação brasileira relativas ao aborto em comparação a outros países. Nele o autor critica os setores conservadores da sociedade que impingem opiniões parciais ao conjunto de sua sociedade democrática e laica. Paixão observa que a descriminalização do aborto não obrigará ninguém a praticar o aborto, mas que essa ação respeitará a consciência individual e os princípios elementares do ordenamento jurídico, que se tornará, segundo o autor, uma realidade concreta. De qualquer modo, o médico e ex-deputado federal (PPS/SE) salienta que todo e qualquer avanço nas possíveis mudanças na legislação através de forças progressistas devem ser vigiadas, pois sempre haverá uma intensa luta dos setores conservadores contra a modernidade democrática que apela para as mais autoritárias práticas de desqualificação através de uma "indisfarçável tendência inquisitorial" (p. 210).

"Aborto no Brasil: obstáculos para o avanço da legislação" é o último artigo dessa coletânea escrito por Jandira Feghali, médica e ex-deputada federal (PCdoB/RJ). Feghali fala sobre a necessidade de ampliar a discussão sobre o aborto, lembrando que, nos últimos anos, a sociedade civil vem observando o debate feito em diversos fóruns através da mídia. Entre outros assuntos, dá destaque à Comissão Tripartite instalada pelo Executivo com o objetivo de revisar a legislação do aborto e as discussões promovidas pela Comissão de Seguridade Social e Família, que acabou por colocar em pauta o Projeto de Lei 1.135, que descriminaliza a prática do aborto no Brasil. No artigo, a autora analisa os obstáculos que impedem a aprovação dessa lei, a qual é considerada por ela um avanço na legislação, além de dar cabo, caso aprovada, à indústria clandestina do aborto. Aborda, nessa discussão, dois aspectos relativos à construção da legislação e à contraposição aos argumentos que colocam o direito constitucional à vida como entrave para a descriminalização do aborto.

O conjunto dos artigos acima é abordado a partir de considerações médicas, políticas, éticas, históricas, filosóficas e jurídicas sobre o tema da legalização e da descriminalização do aborto, o que representa, segundo Silvia Pimentel (p. 7), uma contribuição notória ao debate público no país. A partir das diferentes posições apresentadas, o livro mostra um panorama segundo $\circ$ qual $\circ$ aborto ilegal e inseguro predomina no Brasil, e demonstra o desafio de tratar a questão a partir de uma compreensão humanística, que tem como princípio o respeito aos direitos humanos das mulheres.

\section{Notas}

${ }^{1}$ Marcel MAUSS, 1974.

${ }^{2}$ A CDD é uma Organização Não-Governamental feminista criada em 1993 por teólogas, sociólogas, psicólogas, cientistas da religião e outras profissionais.

${ }^{3}$ Entrevista concedida por Maria José Rosado Nunes, coordenadora do CDD no Brasil, ao Jornal Pequeno: Órgão das Multidões, on line, em 17 de junho de 2007.

\section{Referência bibliográfica}

MAUSS, Marcel. "Ensaio sobre a dádiva: forma e razão da troca nas sociedades arcaicas". In: MAUSS, Marcel. Sociologia e Antropologia. São Paulo: EPU, 1974[1924]. v. 2.

Rozeli Maria Porto Universidade Federal de Santa Catarina Miriam Pillar Grossi Universidade Federal de Santa Catarina 